and price of either of these, which might be made the groundwork for lectures. As it is, we have been compelled to depend upon lectures alone, illustrated by experiments, in which the pupils themselves are allowed to have as much share as possible. I should be much obliged to any of your readers who could direct me to any text-book likely to meet the want I have indicated. We are now intending to combine with the subject named above a little Natural Philosophy; and I may add, that we have already had, some time ago, a twelve months' course on electricity, with experiments.

I think, however, that the whole subject of Science Teaching in schools wants treating by some master hand; and if some such man as Prof. Tyndall, for instance, who, in addition to the highest scientific attainments, knows something about the practical difficulties of the matter, would enter into the whole subject in your columns, advising what to teach, how to teach it, and what books to use, he would, I am sure, confer a real benefit upon Science. We have heard enough about the want of it; we want now to be told by competent authority how the want may be best supplied. And I am able to say from my own personal knowledge that there are heads of schools quite convinced of the importance of - the subject, but utterly ignorant how to set about remedying it. Upon this point I wish to be very emphatic, and indeed it was chiefly for the purpose of urging this that I began this letter, knowing as I do well, both from observation and experience, the practical diffculties of the subject; difficulties which are much, very much, greater than your enthusiastic philosophers have any idea of. I hope, however, that if the subject be taken up at all, it will be by some one practically conversant with it, who can give advice which will be worth taking.

M. A.

\section{Forms of Clouds}

CLOUDy formations worthy of being noticed have been observed by me during the week. On the 8 th $I$ chanced to take a walk with M. Gustave Flourens, who has since been sentenced to death by court-martial. At five o'clock we witnessed many ribboned clouds parallel to each other, and so long that they appeared to radiate from a common focus. These ribboned clouds termicated abruptly just over our heads, and their extremities were noalescent, so that the appearance was one of a feather with the vanes of the quill emanating from one side. The wind was blowing

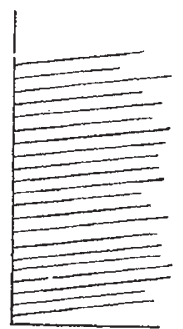

perpendicularly to the vanes and parallel to the quill. This accumulation of matter was evidently owing to the purity of the air on the other side of the singular cloud-edge.

I witnessed again these phenomena on the 9 th and on the roth of March, but not so well. On the 9 th and roth I also observed two solar halos well defined. The halo had a peculiarity of its own. The clouds adjoining the edge were tinged most delicately with violet on the south-easterly side. The evening was stormy and rainy, which is consistent with the theory I have advocated that halos are a prognostic of bad weather.

\section{W. DE Fonyielle}

\section{The Limits of Numerical Discrimination}

THE solution of the Problem "how many objects can a man count at once?" is not general, but depends especially on the grouping, position, angular distance, similarity and nature of the objects counted, as well as on the experience and health of the person who counts them.

(This is written under the supposition that the word "count" means "tell the number of," not "begin, one, two, three," which of course cannot be done simultaneously.)
As an example of the operations performed in counting, take the card "ten of diamonds." The player passes his eyes up and down it, recognises it to be the ten, discriminating it from the other cards, calls it by its name "ten," and then, if he likes, can count separately the pips on the card.

This is a case in which the number of the card is recognised as its name, and many others could be adduced in which much higher numbers arranged symmetrically could be recognised at a glance without counting.

A person habituated to counting would divide the objects into groups with which he was best acquainted, in a way depending on their position.

To show that running the eye over the object is not necessarily conscious, or the very operation of counting-If anyone on a fine sunny day looks through a latticed window for some time and then shuts his eyes, he will be able to count a great number of panes in the impression on his retina, or wherever it is. (Compare with this operation that of recognising a person after he has passed out of sight.)

Looking at a collection of objects in counting by groups is governed by the same laws as looking at a single complex object, and naming follows after the object has been properly discriminated. I can imagine that a person naturally gifted with a memory for form or a certain kind, could by practice at once recognise the number of a large quantity of coins scattered at random, inasmuch as the number would be sharply discriminated from the one higher and the one lower, just as a shepherd discriminates sheep, which to other eyes are alike, and if he can discriminate 36 from 35 and 37 , there is no necessity for hin to count 36 to say that 36 are there. That can be done afterwards. There should be no astonishment that anyone should possess this power, for after all what is it in comparison to the marvellous faculty we have of seeing highly complex objects at once, which we can analyse to a certain extent; but in no way resolve into the elements of the synthesis. The discrimination between red and yellow, between one note and the next, seems to demand much finer powers of the memory; but we are not astonished at it.

The explanation of many wonderful mental and manual feats depends on the same marvellous faculty of apprehending and cousidering as one that which formerly could be only considered as very many. Reading words, playing a musical instrument (whether with or without notes), writing, tying knots, doing needlework, the manufacture of every useful thing, all are acquired through the same faculty of changing several simple movements into one complex movement, which is treated as one, and can be named as one, even before it is analysed. It is only fair to infer that counting by groups is an art which may be learned, and, if worth the while, carried to a high degree of practical excellence.

Your correspondent "J. B." (March 9) illustrates Dugald Stewart's view by the examples of two beans and two eyes; these do not prove anything in regard to mental attention, but only that they were not both opposite the parts of the retina with which the observer could see most comfortably. If they had only a small but perceptible angular distance, and did not dazzle so as to tire the eyes, what he mentions would probably not have occurred. He could remember them both together and then count them as well as if he were actually looking at them.

Eccles, March 14

R. V.

\section{Books Wanted}

Could you kindly inform me where I could obtain the following works mentioned by Sir John Herschel in his "Discourse on Natural Philosophy," viz.-Bracconot, "Annales de Chimie," and "Dr. Prout's Account of the Experiments of Professor Autenrieth, of Tubingen," Phil. Trans. 1827. My efforts to obtain these hooks have hitherto been in vain; if you could assist me, I should feel much obliged.

Newbridge, March 12

H, J. WATSON

\section{Quinary Music}

Your correspondent, Beacon Lough, will find a very effective specimen of this division in the concluding Allegro to the glee "The Gipsy," written by Wm. Reeve.

\section{The Earthquake}

THE earthquake, which caused considerable alarm throughout the North of England on the night of the 17 th, was felt severely here between I1.5 and II.10 P.M. The sky, which had been 